\title{
Evidence for Urate Uptake Through Monocarboxylate Transporter 9 Expressed in Mammalian Cells and Its Enhancement by Heat Shock
}

\author{
Naoyuki Otani, MD, PhD; Yasutaka Kurata, MD, PhD; Nani Maharani, MD, PhD; \\ Masanari Kuwabara, MD, PhD; Nobuhito Ikeda, PhD; Tomomi Notsu, BSc; \\ Peili Li, MD, PhD; Junichiro Miake, MD, PhD; Akio Yoshida, MD, PhD; \\ Hiromi Sakaguchi, MD; Katsumi Higaki, PhD; Naoe Nakasone, PhD; \\ Motokazu Tsuneto, PhD; Yasuaki Shirayoshi, PhD; Motoshi Ouchi, MD, PhD; \\ Haruaki Ninomiya, MD, PhD; Kazuhiro Yamamoto, MD, PhD; \\ Naohiko Anzai, MD, PhD; Ichiro Hisatome, MD, PhD
}

\begin{abstract}
Background: Monocarboxylate transporter 9 (MCT9), an orphan transporter member of the solute carrier family 16 (SLC16), possibly reabsorbs uric acid in the renal tubule and has been suggested by genome-wide association studies to be involved in the development of hyperuricemia and gout. In this study we investigated the mechanisms regulating the expression of human (h) MCT9, its degradation, and physiological functions.
\end{abstract}

\begin{abstract}
Methods and Results: hMCT9-FLAG was stably expressed in HEK293 cells and its degradation, intracellular localization, and urate uptake activities were assessed by pulse-chase analysis, immunofluorescence, and $\left[{ }^{14} \mathrm{C}\right]$-urate uptake experiments, respectively. hMCT9-FLAG was localized on the plasma membrane as well as in the endoplasmic reticulum and Golgi apparatus. The proteasome inhibitors MG132 and lactacystine increased levels of hMCT9-FLAG protein expression with enhanced ubiquitination, prolonged their half-life, and decreased $\left[{ }^{14} \mathrm{C}\right]$-urate uptake. $\left[{ }^{14} \mathrm{C}\right]$-urate uptake was increased by both heat shock (HS) and the HS protein inducer geranylgeranylacetone (GGA). Both HS and GGA restored the $\left[{ }^{14} \mathrm{C}\right]$-urate uptake impaired by MG132.
\end{abstract}

Conclusions: hMCT9 does transport urate and is degraded by a proteasome, inhibition of which reduces hMCT9 expression on the cell membrane and urate uptake. HS enhanced urate uptake through hMCT9.

Key Words: Heat shock; Heat shock protein 70 (HSP70); Hyperuricemia; Monocarboxylate transporter 9; Urate uptake

$\mathbf{U}$ ric acid is the end product of purine metabolism and plays a pivotal role in the regulation of the redox state as an antioxidative substance. ${ }^{1,2}$ The serum uric acid concentration is related to pathological changes: hyperuricemia causes gout, chronic kidney disease and urolithiasis, ${ }^{3}$ whereas hypouricemia is related to uroli- thiasis and exercise-induced acute renal failure. ${ }^{4}$

Serum uric acid concentrations are regulated by both uric acid production and its urinary excretion. After filtration through the glomerulus, $90 \%$ of the filtered uric acid is reabsorbed through uric acid transporters (UATs) in proximal tubular cells. UATs play a crucial role in determining

Received February 18, 2020; revised manuscript received May 16, 2020; accepted May 25, 2020; J-STAGE Advance Publication released online July 2, 2020 Time for primary review: 15 days

Department of Clinical Pharmacology and Therapeutics, Oita University Faculty of Medicine, Oita (N.O.); Department of Physiology II, Kanazawa Medical University, Ishikawa (Y.K.), Japan; Department of Pharmacology and Therapy, Faculty of Medicine Diponegoro University, Semarang (N.M.), Indonesia; Intensive Care Unit and Department of Cardiology, Toranomon Hospital, Tokyo (M.K.); Department of Genetic Medicine and Regenerative Therapeutics, Tottori University Graduate School of Medical Science, Tottori (N.I., T.N., P.L., A.Y., M.T., Y.S., I.H.); Department of Pharmacology (J.M.), Department of Radiology (H.S.), Department of Biological Regulation (N.N., H.N.), Division of Cardiovascular Medicine, Department of Molecular Medicine and Therapeutics (K.Y.), Tottori University Faculty of Medicine, Tottori; Division of Functional Genomics, Tottori University Research Center for Bioscience and Technology, Tottori (K.H.); Department of Pharmacology and Toxicology, Dokkyo Medical University School of Medicine, Tochigi (M.O.); and Department of Pharmacology, Chiba University Graduate School of Medicine, Chiba (N.A.), Japan

I.H. is a member of Circulation Reports' Editorial Team.

Mailing address: Yasutaka Kurata, MD, PhD, Department of Phyisiology II, Kanazawa Medical University, 1-1 Daigaku, Uchinada, Kahoku, Ishikawa 920-0293, Japan. E-mail: yasu@kanazawa-med.ac.jp

All rights are reserved to the Japanese Circulation Society. For permissions, please e-mail: cr@j-circ.or.jp

ISSN-2434-0790 
serum uric acid concentration, and their functional impairment causes either hyperuricemia or hypouricemia. Impairment of the urate anion transporter URAT1 or URATV1 (Glut9) causes renal hypouricemia, ${ }^{\mathbf{5 , 6}}$ whereas impairment of another UAT, namely ATP-binding cassette transporter G2 (ABCG2), causes hyperuricemia and gout. ${ }^{7}$

Monocarboxylate transporter 9 (MCT9; encoded by the solute carrier family 16 member 9 [SLC16 A9] gene) is an orphan transporter member of solute carrier family 16 (SLC16) that possibly reabsorbs uric acid in the renal tubule and has been suggested by genome-wide association studies (GWAS) to be involved in the development of hyperuricemia and gout. ${ }^{8}$ Although the functional characteristics of MCT9 remain to be fully determined, it is expressed in urateexcreting organs, including the intestine and kidney. In previous studies, we reported that MCT9 was expressed in human umbilical endothelial cells, human induced pluripotent stem cell-derived cardiac myocytes, and mouse atrial myocytes.9,10 It has been reported that MCT expression levels are correlated with serum DL-carnitine and propionylL-carnitine concentrations, and strongly correlated with serum uric acid concentrations. ${ }^{8}$ Recently, Anzai et al ${ }^{11}$ reported that MCT9 functions as a transporter of organic solutes, including carnitine, urate, and $\beta$-hydroxybutyrate, but its physiological and pathophysiological roles remain to be elucidated.

Heat shock (HS) induces HS protein (HSP) 70 to increase channel protein expression, with enhancement of its physiological activity. It has been reported that HS and overexpression of HSP70 can increase levels of the voltagegated Kv1.5 channel, ${ }^{12}$ and that heat stress and psychological stress increase serum uric acid concentrations. ${ }^{13,14}$ Thus, HS may increase the renal reabsorption of uric acid through MCT9 by enhancing HSP70 expression.

In the present study we investigated proteasome modification of human (h) MCT9 protein and the effects of hMCT9 on urate uptake, as well as the effects of HS and an HSP inducer on urate uptake via hMCT9, in HEK293 cells. HS and the HSP inducer enhanced urate uptake through hMCT9 both in the absence and presence of a proteasome inhibitor.

\section{Methods}

\section{Cell Culture and Establishment of an hMCT9-Expressing HEK293 Cell Line}

cDNA encoding hMCT9 tagged with a FLAG epitope (hMCT9-FLAG) was cloned in the mammalian expression vector pcDNA3.1(+) (Invitrogen, Carlsbad, CA, USA). The plasmid was transfected into HEK293 cells using Lipofectamine 2000 (ThermoFisher Scientific, Waltham, MA, USA) following the manufacturer's instructions. To establish a cell line that stably expresses hMCT9-FLAG, HEK293 cells were cultured in the presence of $1 \mathrm{mg} / \mathrm{mL}$ geneticin (G418) and the cell clones were then harvested. Expression of hMCT9-FLAG was confirmed by western blotting. Cells stably expressing hMCT9-FLAG were cultured in Dulbecco's modified Eagle's medium (DMEM; Wako, Osaka, Japan) supplemented with 10\% fetal bovine serum (Nichirei Biosciences, Tokyo, Japan) and 0.5\% penicillin-streptomycin $\mathrm{G}$ (Wako) at $37^{\circ} \mathrm{C}$ in a $5 \% \mathrm{CO}_{2}$ incubator.

\section{Drugs}

The proteasome inhibitors benzyloxycarbonylleucyl-leucyl- leucine aldehyde (MG132) and lactacystine, the endosome inhibitor chloroquine, and the HSP inducer geranylgeranylacetone (GGA) were dissolved in dimethylsulfoxide (DMSO). The final concentration of DMSO in the culture medium was $\leq 0.01 \%(\mathrm{v} / \mathrm{v})$. MG132 was purchased from Sigma-Aldrich (St. Louis, MO, USA). GGA was kindly donated by Eisai (Tokyo, Japan).

\section{Western Blotting and Immunoprecipitation}

Cells were scraped into lysis buffer (phosphate-buffered saline [PBS] with 1\% Nonidet P-40, 0.5\% sodium deoxycholate, $0.1 \%$ sodium dodecyl sulfate, $10 \mu \mathrm{g} / \mathrm{mL}$ aprotinin, $10 \mu \mathrm{g} / \mathrm{mL}$ leupeptin, $10 \mu \mathrm{g} / \mathrm{mL}$ pepstatin, and $1 \mathrm{mmol} / \mathrm{L}$ phenylmethylsulfonyl fluoride) and lysed by sonication; insoluble materials were removed by centrifugation $\left(15,000 \mathrm{rpm}, 10 \mathrm{~min}, 4^{\circ} \mathrm{C}\right)$. Protein concentrations were determined using a commercially available protein assay kit (Bio-Rad, Hercules, CA, USA). Proteins $(10 \mu \mathrm{g})$ were separated by $7.5 \%$ sodium dodecyl sulfate (SDS)-polyacrylamide gel electrophoresis (PAGE) and electrotransferred to polyvinylidene difluoride membranes (Immobilon-P; Millipore, Bedford, MA, USA). The membranes were probed with antibodies against FLAG (1:1,000; Agilent Technologies, Santa Clara, CA, USA), HSP70 (1:1,000; Stressgen, San Diego, CA, USA), HSP90 (1:1,000; Cosmo Bio, Tokyo, Japan), and $\beta$-actin (1:5,000; Abcam, Tokyo, Japan), and were developed using an enhanced chemiluminescence (ECL) system (Amersham, Piscataway, NJ, USA). Immunoprecipitation was performed in PBS containing $1 \%$ Triton $\mathrm{X}-100,0.5 \%$ SDS, $0.25 \%$ sodium deoxycholate, $1 \mathrm{mmol} / \mathrm{L}$ EDTA, and protease inhibitors for $2 \mathrm{~h}$ at $4^{\circ} \mathrm{C}$. Immune complexes were collected with protein $\mathrm{G}$ agarose (Pharmacia, Uppsala, Sweden) and bound proteins were analyzed by SDS-PAGE and immunoblotting.

\section{Chase Assay}

HEK293 cells stably expressing hMCT9-FLAG were seeded in 6-well plates. After the addition of the protein synthesis inhibitor cycloheximide $(60 \mu \mathrm{g} / \mathrm{mL})$, protein extracts were prepared at the indicted time points and subjected to antiFLAG western blotting. Band intensity was quantified using ImageJ software (National Institutes of Health, Bethesda, MD, USA). The decay rate constant ( $k$ ) for the density of hMCT9-FLAG proteins was determined by fitting the data with a single exponential function; the half-life $\left(t_{1 / 2}\right)$ of the protein was calculated using the formula $t_{1 / 2}=0.693 / k$.

\section{Immunofluorescence}

HEK293 cells stably expressing hMCT9-FLAG were seeded on gelatin-coated coverslips and transfected with either a pmCherry-PM, pDsRed2-ER, or pDsRed-Golgi vector (all from Clontech, Mountain View, CA, USA) to detect the plasma membrane, endoplasmic reticulum (ER), and Golgi apparatus, respectively. Twenty-four hours later, cells were fixed with 4\% paraformaldehyde in PBS and then permeabilized with $0.5 \%$ Triton X-100. After blocking in $3 \%$ albumin solution diluted with PBS containing 0.5\% Triton X-100, cells were incubated for $1 \mathrm{~h}$ with the antiFLAG antibody (1:1,000; Agilent Technologies). Bound antibodies were visualized with Alexa Fluor 488-conjugated mouse secondary antibody (1:2,000; Invitrogen, Eugene, OR, USA), and images were obtained using a Bio-Rad (Hercules, CA, USA) MRC 1024 confocal microscope. All staining procedures were conducted at room temperature. 


\begin{tabular}{|c|c|c|}
\hline \multirow{2}{*}{ Gene } & \multicolumn{2}{|c|}{ Primer sequence (5'-3') } \\
\hline & Forward & Reverse \\
\hline \multicolumn{3}{|l|}{ RT-PCR } \\
\hline URAT1 (s/c22A12) & CAGTCCATCTTCCTGGCTGG & AGCTTGCCCACCGTGATGAG \\
\hline URATv1 (s/c2A9) & GAGGAGGACAAAGAAATGGTCC & ATCACTCCGAACAGGTATGGC \\
\hline$A B C G 2$ & ССТАCAACAACCCTGCGGAT & ACTACGAACAGCTCCACAGC \\
\hline NPT1 (s/c17a1) & GATGTCCTTGCTCCTCCCAC & TGGTGAAGAGTTTCCGGACG \\
\hline NPT4 (s/c17a3) & TCACACTGATGGCGCAGAAT & ACTAATGATGCCGCCCACAA \\
\hline OAT1 (s/c22a6) & ACCTTGTGTGCTCTCATCGG & AACTGGCCCAAGCTGTAGAC \\
\hline OАT3 (s/c22a8) & CTTCCGATTCCTGTGTGGCT & TAGCCACACGTTGGAGTGTC \\
\hline MRP4 & CGTTAATTGAGGCACTCCGGT & GGTAGGAGCTGCCCAGAATC \\
\hline МСT9 & ССTTCCTAAAAGCCTCGCCA & CCCAAAAGAAGCTTGCCCAC \\
\hline \multicolumn{3}{|l|}{ Real-time qPCR } \\
\hline URATv1 (s/c2A9) & CCTGGGGAGCTCTCTGTG & GAGCGAGAAGGACCATTTCTT \\
\hline$A B C G 2$ & GCCTTGGAGTACTTTGCATCA & AAATCCGCAGGGTTGTTGTA \\
\hline MRP4 & TGAAGCAACTGCAAATGTGG & TGTGAGCAATGGTGAGCACT \\
\hline МСT9 & CCTCGGCCTGATTTCAAC & AGCAGGCAGCCATCTAGG \\
\hline
\end{tabular}

ABCG2, ATP-binding cassettes subfamily G second member 2; MCT9, monocarboxylate transporter 9; MRP4 multidrug resistance protein 4; NPT1, sodium-phosphate transporter 1; NPT4, sodium-phosphate transporter 4; OAT1, organic anion transporter 1; OAT3, organic anion transporter 3; slc17a1, solute carrier family 17 member 1; slc17a3, solute carrier family 17 member 3; slc22a12, solute carrier family 22 member 12; slc22a6, solute carrier family 22 member 6; slc22a8, solute carrier family 22 member 8; scl2a9, solute carrier family 2 member 9; URAT1, urate transporter 1; URATv1, voltage-driven urate efflux transporter 1.

\section{Measurement of Uric Acid Uptake}

The kinetic behavior of UATs was examined by uptake studies using confluent HEK293/hMCT9-FLAG cells. After 2 days of culture in 24-well plates, cells were washed twice with serum- and chloride-free Hanks' balanced salt solution (HBSS) containing $125 \mathrm{mmol} / \mathrm{L} \mathrm{Na}$ gluconate, $4.8 \mathrm{mmol} / \mathrm{L}$ $\mathrm{K}$ gluconate, $1.2 \mathrm{mmol} / \mathrm{L} \mathrm{KH}_{2} \mathrm{PO}_{4}, 1.2 \mathrm{mmol} / \mathrm{L} \mathrm{MgSO}_{4}$, $1.3 \mathrm{mmol} / \mathrm{L} \mathrm{Ca}$ gluconate, $5.6 \mathrm{mmol} / \mathrm{L}$ glucose, and $25 \mathrm{mmol} / \mathrm{L}$ HEPES (pH adjusted to 7.4 with $\mathrm{NaOH}$ ), and then preincubated in the same HBSS in a water bath at $37^{\circ} \mathrm{C}$ for $10 \mathrm{~min}$. The cells were then incubated in HBSS containing $5 \mu \mathrm{mol} / \mathrm{L}\left[{ }^{14} \mathrm{C}\right]$-urate at $37^{\circ} \mathrm{C}$ for $1-10 \mathrm{~min}$. Uptake was stopped by the addition of ice-cold HBSS, and the cells were then washed twice with the same HBSS. The cells in each well were lysed with $0.5 \mathrm{~mL}$ of $0.1 \mathrm{~mol} / \mathrm{L}$ sodium hydroxide, and added to $2.5 \mathrm{~mL}$ INSTA-GEL PLUS (Perkin Elmer, Yokohama, Japan). Radioactivity was determined using a $\beta$-scintillation counter (LSC-3100; Aloka, Tokyo, Japan). To evaluate uric acid uptake via hMCT9, the uptake of $\left[{ }^{14} \mathrm{C}\right]$-urate was determined in the absence and presence of the MTC9 inhibitor benzbromarone $(10 \mu \mathrm{mol} / \mathrm{L})$.

\section{Induction of HS and HSPS}

Cells were cultured in 24-well tissue culture plates at a density of $1 \times 10^{5}$ cells/well. After the cells had been cultured for 2 days at $37^{\circ} \mathrm{C}$, they were incubated at $42^{\circ} \mathrm{C}$ for $12 \mathrm{~h}$ to induce HS. For pharmacological induction of HSPs (HSP70 and HSP90), cells were exposed to the HSP inducer GGA $(0.3 \mu \mathrm{mol} / \mathrm{L})$ for $12 \mathrm{~h}$.

\section{mRNA Extraction and Polymerase Chain Reaction}

Total RNA was extracted from mouse organs using an RN-easy kit (Qiagen, Venlo, Netherlands). cDNA was synthesized using PrimeScript with gDNA eraser (Takara Bio, Kusatsu, Japan) according to the manufacturer's protocol. The primers used for reverse transcriptionpolymerase chain reaction (RT-PCR) and real-time quantitative polymerase chain reaction (qPCR) are listed in Table.

\section{Statistical Analysis}

All data are expressed as the mean \pm SEM. Comparisons were made using Student's t-test, with 2-sided $\mathrm{P}<0.05$ considered significant.

\section{Results}

\section{Effects of MG132 on Degradation of hMCT9 Proteins}

hMCT9-FLAG expressed in HEK293 cells was detected by anti-FLAG western blotting at $56 \mathrm{kDa}$, the predicted size of full-length hMCT9-FLAG (Figure 1A). The chase experiment showed that the density of hMCT9-FLAG decreased in a time-dependent manner; treatment with the proteasome inhibitor MG132 $(5 \mu \mathrm{mol} / \mathrm{L}$ for $12 \mathrm{~h})$ increased the density of the band and slowed the decay process, suggesting that MG132 induced stabilization of hMCT9FLAG (Figure 1B). The control $t_{1 / 2}$ of hMCT9-FLAG degradation was $3.55 \pm 0.78 \mathrm{~h}(\mathrm{n}=4)$, and was significantly prolonged to $11.05 \pm 6.2 \mathrm{~h}(\mathrm{n}=4)$ in cells treated with MG132 (Figure 1C). Next, we examined whether hMCT9 molecules could be ubiquitinated more prominently in the presence of another proteasome inhibitor, namely lactacystine $(25 \mu \mathrm{mol} / \mathrm{L})$, and the endosome inhibitor chloroquine $(2 \mathrm{mmol} / \mathrm{L})$. As shown in Supplementary Figure 1, lactacystine but not chloroquine increased protein levels of hMCT9-FLAG and ubiquitinated hMCT9-FLAG. These results indicate that hMCT9 is ubiquitinated and degraded through a proteasome.

\section{Intracellular Localization of hMCT9-FLAG}

Next we examined the intracellular localization of hMCT9- 


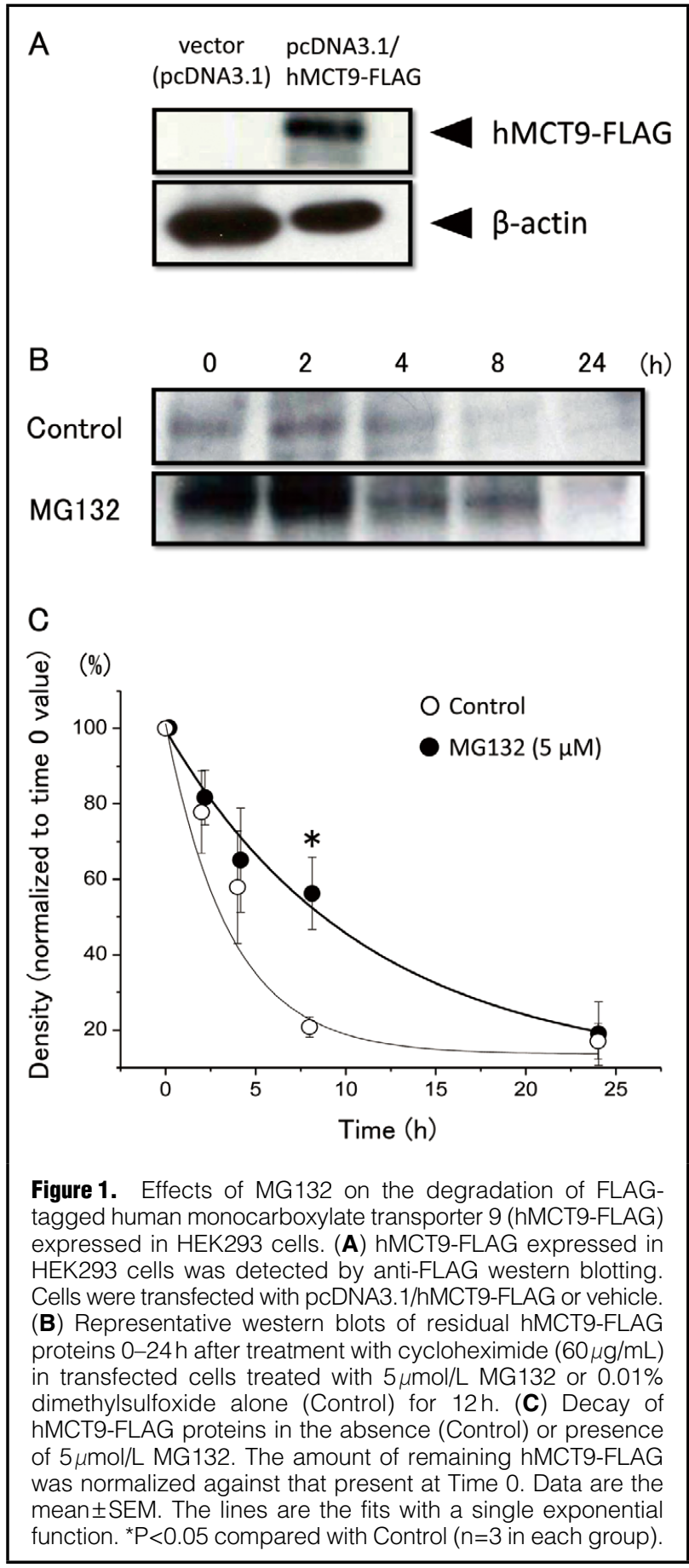

FLAG by immunofluorescence. Anti-FLAG staining of HEK293/hMCT9-FLAG cells revealed that hMCT9FLAG localized in the ER and Golgi apparatus, as well as on the plasma membrane, as shown by colocalization of DsRed2-ER, DsRed-Golgi, and mCherry-PM staining (Figure 2). We found no colocalization of hMCT9-FLAG with endosome-enhanced green fluorescent protein (data not shown).

Effects of MG132 on Urate Uptake Through hMCT9-FLAG Stabilization of hMCT9-FLAG induced by proteasome inhibition may lead to enhanced uric acid transport. There-

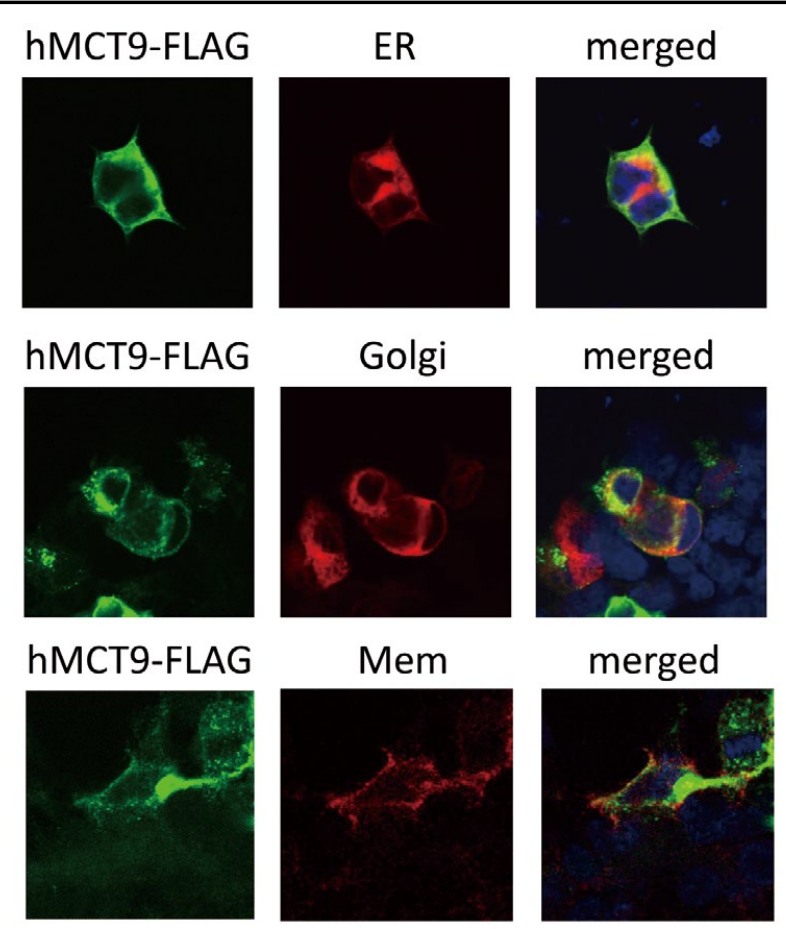

Figure 2. Intracellular localization of FLAG-tagged human monocarboxylate transporter 9 (hMCT9-FLAG). Representative immunofluorescence images obtained by confocal microscopy are shown for hMCT9-FLAG and DsRed2-ER (Top), DsRedMonomer-Golgi (Middle), and mCherry-PM (Bottom) to detect the endoplasmic reticulum (ER), Golgi apparatus, and plasma membrane (Mem), respectively.

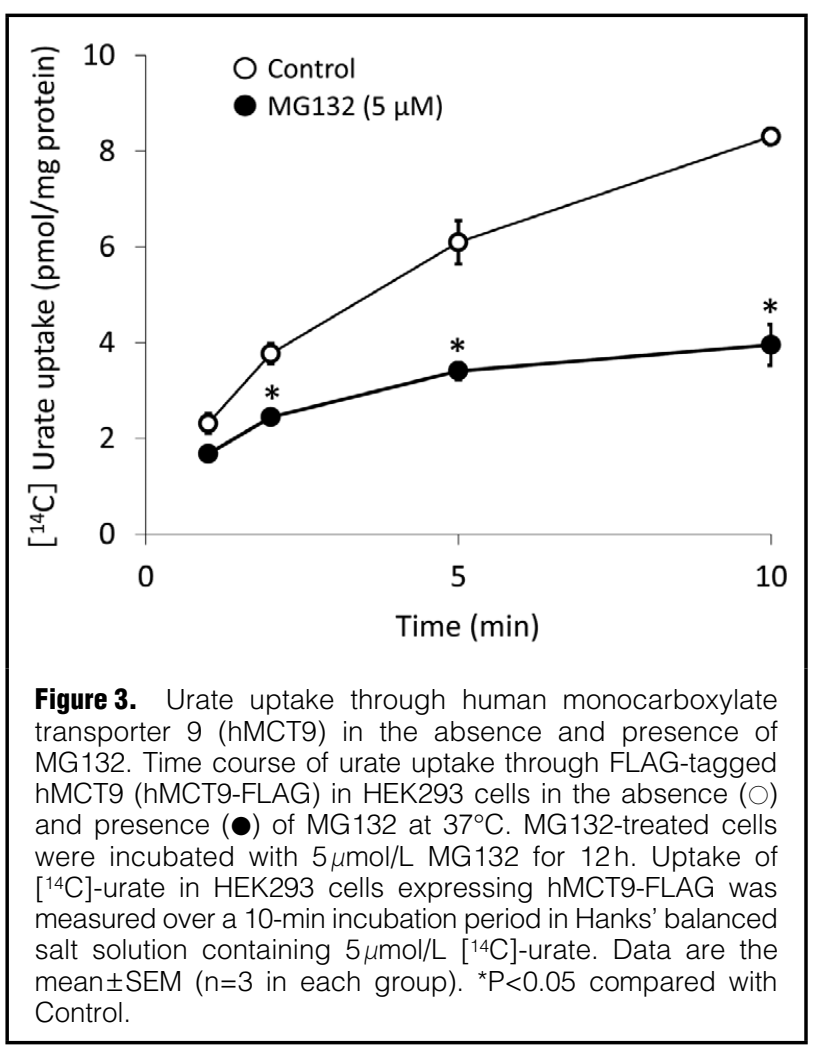



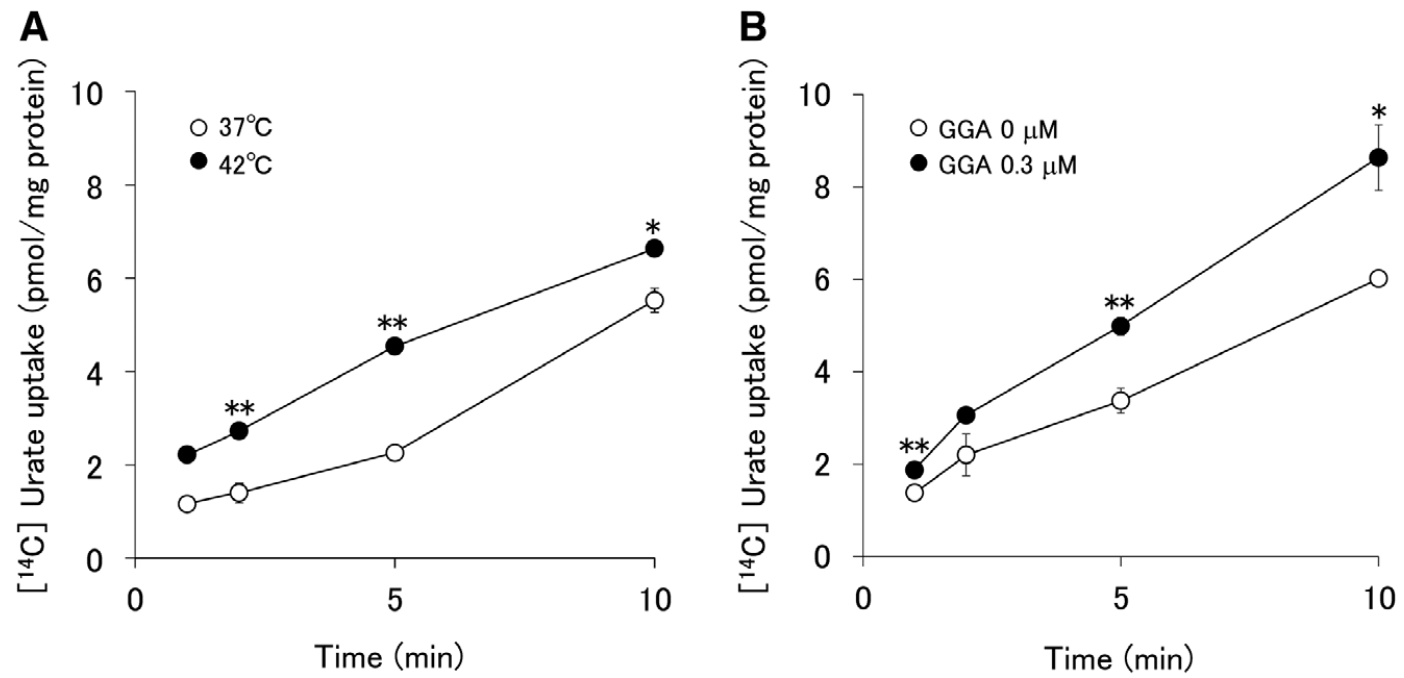

Figure 4. Effects of heat shock (HS) and geranylgeranylacetone (GGA) on urate uptake through human monocarboxylate transporter 9 (hMCT9) in the absence of MG132. (A) After 12-h incubation in control Hanks' balanced salt solution (HBSS) at $37^{\circ} \mathrm{C}$ $(\bigcirc)$ or $42^{\circ} \mathrm{C}(\bullet)$, the time course of urate uptake over a 10-min incubation period in HBSS containing $5 \mu \mathrm{mol} / \mathrm{L}\left[{ }^{14} \mathrm{C}\right]$-urate was determined at $37^{\circ} \mathrm{C}$. (B) The time course of $\left[{ }^{14} \mathrm{C}\right]$-urate uptake was also examined in the absence $(\bigcirc)$ and presence $(\bullet)$ of GGA at $37^{\circ} \mathrm{C}$. The GGA-treated group cells were incubated with $0.3 \mu \mathrm{mol} / \mathrm{L} \mathrm{GGA}$ for $12 \mathrm{~h}$ before uptake measurements. Data are the mean \pm SEM ( $n=3$ in each group). ${ }^{*} \mathrm{P}<0.05$, ${ }^{*} \mathrm{P}<0.01$ compared with $37^{\circ} \mathrm{C}(\mathbf{A})$ or $0 \mu \mathrm{M} G \mathrm{GA}(\mathbf{B})$.
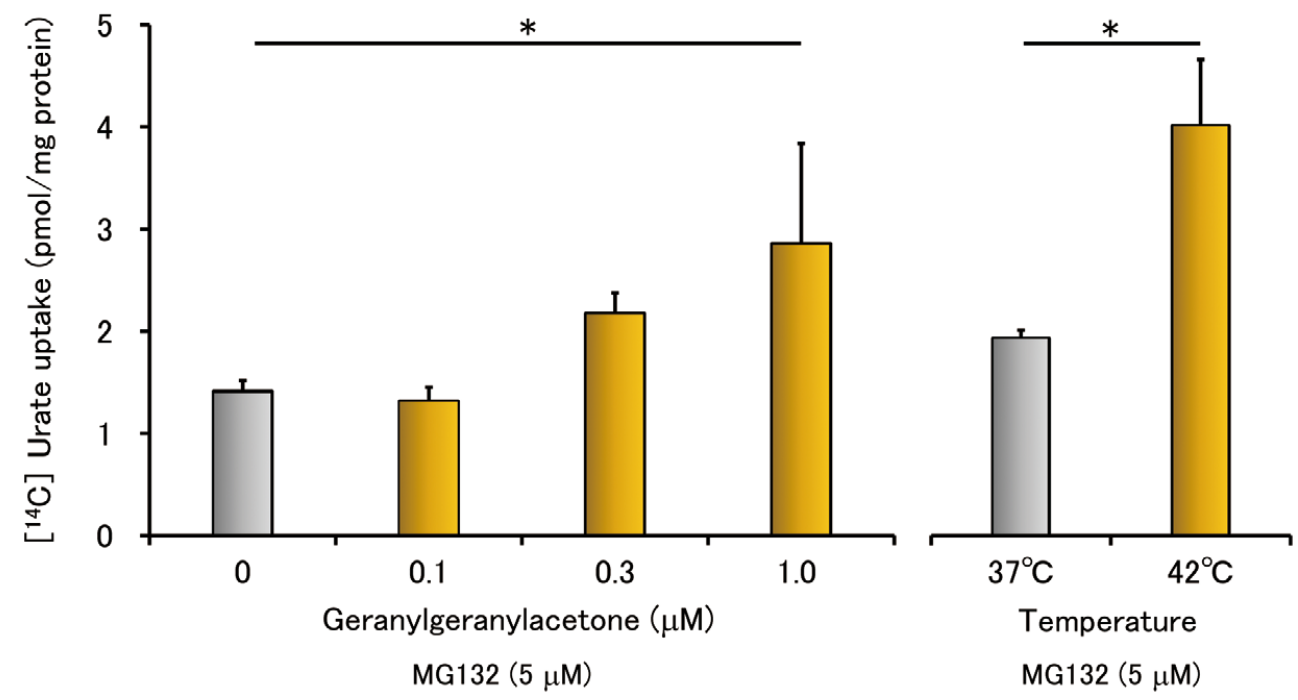

Figure 5. Effects of heat shock (HS) and geranylgeranylacetone (GGA) on urate uptake through human monocarboxylate transporter 9 (hMCT9) in the presence of MG132. GGA-treated group cells were incubated with $0,0.1,0.3$ and 1.0 $\mu$ mol/L GGA for $12 \mathrm{~h}$ in the presence of $5 \mu \mathrm{mol} / \mathrm{L} \mathrm{MG132}$ at $37^{\circ} \mathrm{C}$ (Left). Uptake of $\left[{ }^{14} \mathrm{C}\right]$-urate was measured after 2 min incubation in Hanks' balanced salt solution (HBSS) containing $5 \mu \mathrm{mol} / \mathrm{L}\left[{ }^{14} \mathrm{C}\right]-$ urate. $\left[{ }^{14} \mathrm{C}\right]$-Urate uptake over $2 \mathrm{~min}$ was also determined after incubation of cells for $8 \mathrm{~h}$ in control HBSS at $37^{\circ} \mathrm{C}$ or $42^{\circ} \mathrm{C}$ (Right). Urate uptake, which was reduced by MG132, was restored to control levels by HS and GGA. Data are the mean \pm SEM ( $n=3$ in each group). ${ }^{*} P<0.05$.

fore, we examined $\left[{ }^{14} \mathrm{C}\right]$-urate uptake in HEK293/hMCT9FLAG cells in the absence and presence of MG132. The urate uptake activity over the range $1-10 \mathrm{~min}$ was much lower for native HEK293 cells than for HEK293 cells transfected with hMCT9-FLAG plasmid, as shown in
Supplementary Figure 2 for the first 2 min of uptake. $\left[{ }^{14} \mathrm{C}\right]-$ Urate uptake by HEK293/hMCT9-FLAG cells was time dependent. Urate uptake in HEK293/hMCT9-FLAG cells treated with $5 \mu \mathrm{mol} / \mathrm{L}$ MG132 for $12 \mathrm{~h}$ was significantly less than that in untreated cells (Figure 3), indicating that 
proteasome inhibition by MG132 reduced urate uptake via hMCT9-FLAG while stabilizing hMCT9-FLAG proteins. Supplementary Figure 3 shows the plasma membrane localization of hMCT9-FLAG in the absence and presence of $5 \mu \mathrm{mol} / \mathrm{L} \mathrm{MG132.} \mathrm{When} \mathrm{cells} \mathrm{were} \mathrm{treated} \mathrm{with} \mathrm{MG132,}$ the signals for hMCT9-FLAG did not colocalize with mCherry-PM. Thus, MG132 reduced the plasma membrane expression of hMCT9-FLAG and decreased urate uptake.

\section{Effects of HS and GGA on Urate Uptake of hMCT9}

Because HS and HSP inducers are known to facilitate the conversion of premature forms of proteins to their mature forms,${ }^{12}$ we examined whether they increase the activity of hMCT9-FLAG. Time-dependent $\left[{ }^{14} \mathrm{C}\right]$-urate uptake by cells expressing hMCT9-FLAG was measured at $37^{\circ} \mathrm{C}$ and $42^{\circ} \mathrm{C}$. Urate uptake through hMCT9-FLAG was significantly augmented at $42^{\circ} \mathrm{C}$ (Figure 4A). GGA, a non-toxic acyclic isoprenoid compound, has been reported to increase HSP70 expression through activation of HS factor 1. Supplementary Figure 4 shows the increases in HSP70 and HSP90 induced by $0.3 \mu \mathrm{mol} / \mathrm{L}$ GGA. As shown in Figure 4B, $0.3 \mu \mathrm{mol} / \mathrm{L}$ GGA significantly increased urate uptake through hMCT9-FLAG. We next examined whether HS or GGA could restore the impaired urate uptake activity of hMCT9-FLAG in cells treated with MG132. As shown in Figure 5, even in cells treated with $5 \mu \mathrm{mol} / \mathrm{L} \mathrm{MG132,}$ urate uptake was increased significantly by $1.0 \mu \mathrm{mol} / \mathrm{L} \mathrm{GGA}$ and $42^{\circ} \mathrm{C} \mathrm{HS}$ to levels seen in MG132-untreated cells.

\section{Discussion}

In the present study we found that: (1) degradation of hMCT9-FLAG was slowed by the proteasome inhibitor MG132; (2) hMCT9-FLAG localized in the ER/Golgi apparatus and on the plasma membrane; (3) MG132 reduced hMCT9-FLAG expression on the cell membrane and urate uptake through hMCT9-FLAG; and (4) both HS and the HSP inducer GGA enhanced urate uptake through hMCT9-FLAG.

MCT9, a member of the monocarboxylate cotransporter family, was reported to be predominantly expressed at high levels in the kidney. ${ }^{15}$ SLC16A9, which encodes MCT9, was identified from an analysis of human genome expressed sequence tag (EST) databases. ${ }^{\mathbf{1 5}}$ In the present study, we demonstrated MCT9-mediated urate uptake using HEK293 cells (Supplementary Figure 2A), although there is no direct evidence that MCT9 is involved in urate reabsorption in the kidney. A relationship between MCT9 or SLC16A9 and serum uric acid concentrations was determined using meta-analyses of GWAS. ${ }^{16}$ Genotyping of the rs12356193 single nucleotide polymorphism within the $S L C 16 A 9$ gene revealed that it was associated with DL-carnitine, propionylL-carnitine, and serum uric acid concentrations. ${ }^{8}$ Recent studies showed that MCT9 is expressed in urate-excreting organs (not only in the kidney, but also in the intestines) and suggested that the increase in serum uric acid concentrations in rs12356193 carriers could be due to a reduction in extrarenal urate excretion by MCT9.,17 Because another common missense variant of $S L C 16 A 9$, namely rs2242206, which is predominantly found in the Japanese population, was associated with the risk of renal overload gout (reduced extrarenal urate excretion) but not renal underexcretion gout, MCT9 may have a possible physiological role in urate excretion from human intestinal epithelial cells where MCT9 expression is observed. ${ }^{\mathbf{1 7}}$
When stably expressed in HEK293 cells, hMCT9-FLAG had a short $t_{1 / 2}$ of $<5 \mathrm{~h}$; the proteasome inhibitor MG132 prolonged the $t_{1 / 2}$ and increased the steady state levels of the protein (Figure 1). Similar effects were observed with another proteasome inhibitor, namely lactacystine, but not with the lysosomal inhibitor chloroquine (Supplementary Figure 1). These results indicate that hMCT9-FLAG is degraded by the proteasome.

The mechanisms by which ion channels are degraded have been well studied. It is accepted that immature channel proteins localized in the ER/Golgi apparatus can be degraded by the proteasome. Connexin 43 on the cell surface undergoes ubiquitination and proteasomal degradation, indicating that the mature protein on the cell surface can also be a target of proteasomal degradation. ${ }^{18,19}$ Recently, it was reported that the mature form of human ether-a-go-go-related gene (hERG) proteins on the plasma membrane is ubiquitinated and degraded through the endosome. ${ }^{20}$ There also are a few reports on the degradation of UATs, including that: (1) URAT1 undergoes lysosomal degradation;21 (2) URAT1 is stabilized on the membrane by binding to anchoring proteins with its PDZ domain;22 and (3) URATv1 (Glut9) is degraded through the endosome. ${ }^{23}$ In the present study, MG132 reduced both urate transport through MCT9-FLAG (Figure 3) and MCT9FLAG levels on the plasma membrane (Supplementary Figure 3). Because proteasome inhibition by MG132 increased total cellular levels of hMCT9-FLAG (Figure 1), the main sites of proteasomal degradation of hMCT9 are likely to be the ER and Golgi apparatus.

It is interesting that MG132 reduced membrane expression of hMCT9-FLAG (Supplementary Figure 3) and the hMCT9 activity of urate uptake (Figure 3) while enhancing total hMCT9 expression. There are several controversial findings related to the effects of proteasome inhibitors on the function of ion channels. For example, inhibition of the ubiquitin-proteasome system increased the activity of epithelial $\mathrm{Na}^{+}$channels ${ }^{24}$ and Kv1.5 channels on the plasma membrane, ${ }^{25}$ whereas it failed to affect the channel activity of cystic fibrosis transmembrane conductance regulator $(\mathrm{CFTR})^{26}$ and hERG. ${ }^{27}$ It has also been reported that proteasome inhibition induces the accumulation of insoluble (premature) forms of CFTR but not the accumulation of soluble (mature) CFTR. ${ }^{26}$ Thus, the stabilization and accumulation of the premature form of hMCT9 by the proteasome inhibitor MG132 may interfere with the transport of the mature form of hMCT9 to the cell surface. The proteasome inhibitor lactacystine increased ubiquitinated hMCT9 levels, which may also inhibit membrane trafficking of the mature form of hMCT9. Further experiments are required to elucidate the mechanism underlying the decrease in cell surface expression of hMCT9. Clinically, a specific E3 ligase mediating hMCT9 ubiquitination may be a novel target for the treatment of gout and hyperuricemia to decrease urate reuptake from the kidney. So far, the E3 ligase for hMCT9 remains unknown; thus, further investigations are needed.

The most prominent finding of the present study is that both HS and the HSP inducer GGA accelerated urate uptake through hMCT9-FLAG. HS and GGA are well known to increase HSPs, such as HSP70, and facilitate maturation of short-lived proteins. ${ }^{13,14}$ We have also reported that HSP70 increases the activity of Kv1.5 and hERG channels. ${ }^{13,14}$ Because GGA increased HSP70 (Supplementary Figure 4), enhancement of HSP70 expres- 
sion could facilitate a transition of the premature form of hMCT9 to its mature form, and the transport of mature hMCT9 to the plasma membrane, leading to enhanced urate uptake through hMCT9. This action involving HSP70 was observed even in the presence of MG132, because both HS and GGA restored the impaired urate uptake induced by MG132 (Figure 4B). Together, the findings indicate that, under physiological conditions, certain amounts of premature hMCT9 are synthesized in the ER, and that under stress conditions HSP70 facilitates the maturation of hMCT9, membrane expression of the mature form, and its function of urate uptake.

Although the mechanism underlying the post-translational regulation of hMCT9 by HSP70 remains to be elucidated, the clinical implications are obvious. It is known that heat stress and psychological stress increase serum uric acid concentrations. ${ }^{28,29}$ According to the results of the present study, heat stress can facilitate the transition of the premature form hMCT9 to the mature form and the expression of mature hMCT9 on the cell membrane, thus increasing urate uptake through hMCT9 in the kidney, which, in turn, may cause hyperuricemia.

The findings of this study also have significant implications for cardiology and cardiovascular medicine because MCT9 is also expressed in the cardiovascular system. The RT-PCR and real-time qPCR experiments in this study demonstrated the expression of MCT9 in mouse atrial, ventricular, and aortic tissues (Supplementary Figure 5). MCT9 would facilitate the transport of uric acid into the cells in these tissues, increasing intracellular uric acid concentrations and contributing to the effects of uric acid on the cells. Intracellular accumulation of uric acid is known to cause pathological changes in the cells. For example, in human vascular smooth muscle cells, accumulation of uric acid is responsible for C-reactive protein expression, implicated in cell proliferation and impaired nitric oxide production. ${ }^{30}$ In mouse atrial myocytes, accumulation of uric acid increased the expression of Kv1.5 channels and the ultra-rapid delayed-rectifier $\mathrm{K}^{+}$current (IKur), which leads to shortening of the action potential duration, a prerequisite condition for atrial fibrillation. ${ }^{31}$ Together, these observations indicate that activation of MCT9 may cause the remodeling of vascular cells and atrial myocytes.

The present study has some limitations. First, because of the lack of an antibody against endogenous hMCT9 itself, we used hMCT9-FLAG expressed in a heterologous expression system. The FLAG tag may affect the localization of hMCT9 in transfected cells. Second, in the present study we could not exclude the possibility that MG132 decreased urate uptake via hMCT9 through other mechanisms, such as activation of apoptosis signals, because inhibition of proteasome function is known to induce neuronal cell death by activating the mitochondria-mediated apoptotic cascade, which involves the release of cytochrome $c$ and the activation of caspases. ${ }^{32-34}$ Therefore, in the future, we should examine whether apoptotic cell death is involved in the MG132-induced reduction in urate uptake.

\section{Sources of Funding}

This study was supported by research grants from Teijin Pharma, Fuji Yakuhin Co. Ltd. and Sanwa Kagaku Kenkyusho Co. Ltd. (to I.H.).

\section{Disclosures}

I.H. reports receiving lecturer fees from Mochida Pharmaceutical Company, Sanwa Kagaku Kenkyusho Co. Ltd., Pfizer Co. Ltd.,
Teijin Pharma Co. Ltd., and Fuji Yakuhin Co. Ltd., and research grants from Mochida Pharmaceutical Company, Teijin Pharma Co. Ltd., Fuji Yakuhin Co. Ltd., and Sanwa Kagaku Kenkyusho Co. Ltd.

I.H. is a member of Circulation Reports' Editorial Team. The other authors report no conflicts of interest.

\section{References}

1. Sugihara S, Hisatome I, Kuwabara M, Niwa K, Maharani N, Kato M, et al. Depletion of uric acid due to SLC22A12 (URAT1) loss-of-function mutation causes endothelial dysfunction in hypouricemia. Circ J 2015; 79: 1125-1132.

2. Ames BN, Cathcart R, Schwiers E, Hochstein P. Uric acid provides an antioxidant defense in humans against oxidant- and radical-caused aging and cancer: A hypothesis. Proc Natl Acad Sci USA 1981; 78: 6858-6862.

3. Waring WS, McKnight JA, Webb DJ, Maxwell SR. Uric acid restores endothelial function in patients with type 1 diabetes and regular smokers. Diabetes 2006; 55: 3127-3132.

4. Ichida K, Hosoyamada M, Hisatome I, Enomoto A, Hikita M, Endou $\mathrm{H}$, et al. Clinical and molecular analysis of patients with renal hypouricemia in Japan: Influence of URATI gene on urinary urate excretion. J Am Soc Nephrol 2004; 15: 164-173.

5. Enomoto A, Kimura H, Chairoungdua A, Shigeta Y, Jutabha P, $\mathrm{Cha} \mathrm{SH}$, et al. Molecular identification of a renal urate anion exchanger that regulates blood urate levels. Nature 2002; 417: $447-452$.

6. Anzai N, Ichida K, Jutabha P, Kimura T, Babu E, Jin CJ, et al. Plasma urate level is directly regulated by a voltage-driven urate efflux transporter URATv1 (SLC2A9) in humans. $J$ Biol Chem 2008; 283: 26834-26838.

7. Matsuo H, Takada T, Ichida K, Nakamura T, Nakayama A, Ikebuchi Y, et al. Common defects of ABCG2, a high-capacity urate exporter, cause gout: A function-based genetic analysis in a Japanese population. Sci Transl Med 2009; 1: 5ra11.

8. Kolz M, Johnson T, Sanna S, Teumer A, Vitart V, Perola M, et al. Meta-analysis of 28,141 individuals identifies common variants within five new loci that influence uric acid concentrations. PLoS Genet 2009; 5: e1000504.

9. Mishima M, Hamada T, Maharani N, Ikeda N, Onohara T, Notsu T, et al. Effects of uric acid on the NO production of HUVECs and its restoration by urate lowering agents. Drug Res (Stuttg) 2016; 66: 270-274.

10. Mahati E, Li P, Kurata Y, Maharani N, Ikeda N, Sakata S, et al. $\mathrm{M}_{3}$ muscarinic receptor signaling stabilizes a novel mutant human ether-a-go-go-related gene channel protein via phosphorylation of heat shock factor 1 in transfected cells. Circ J 2016; 80: $2443-2452$.

11. Anzai N, Jutabha P, Ouchi M, Furihata T. Functional characterization of monocarboxylate transporter 9 as a multi-functional organic solute transporter (MFOST). J Physiol Sci 2018; 68(Suppl 1): S53 (abstract).

12. Hirota $Y$, Kurata $Y$, Kato M, Notsu T, Koshida S, Inoue T, et al. Functional stabilization of Kv1.5 protein by Hsp70 in mammalian cell lines. Biochem Biophys Res Commun 2008; 372: 469-474.

13. Ting YK, Morikawa K, Kurata Y, Li P, Bahrudin U, Mizuta E, et al. Transcriptional activation of the anchoring protein SAP97 by heat shock factor (HSF)-1 stabilizes K(v)1.5 channels in HL-1 cells. Br J Pharmacol 2011; 162: 1832-1842.

14. Li P, Ninomiya H, Kurata Y, Kato M, Miake J, Yamamoto Y, et al. Reciprocal control of hERG stability by Hsp70 and Hsc70 with implication for restoration of LQT2 mutant stability. Circ Res 2011; 108: $458-468$.

15. Halestrap AP, Price NT. The proton-linked monocarboxylate transporter (MCT) family: Structure, function and regulation. Biochem J 1999; 343: 281-299.

16. Phipps-Green AJ, Merriman ME, Topless R, Phipps-Green AJ, Merriman ME, Topless R, et al. Twenty-eight loci that influence serum urate levels: Analysis of association with gout. Ann Rheum Dis 2016; 75: 124-130.

17. Nakayama A, Matsuo H, Shimizu T, Ogata H, Takada Y, Nakashima $\mathrm{H}$, et al. Common missense variant of monocarboxylate transporter 9 (MCT9/SLC16A9) gene is associated with renal overload gout, but not with all gout susceptibility. Hum Cell 2013; 26: $133-136$.

18. Saffitz JE, Laing JG, Yamada KA. Connexin expression and turnover: Implication of cardiac excitability. Circ Res 2000; 86: $723-728$.

19. Cheng SH, Gregory RJ, Marshall J, Paul S, Souza DW, White 
GA, et al. Defective intracellular transport and processing of CFTR is the molecular basis of most cystic fibrosis. Cell 1990; 63: $827-834$.

20. Guo J, Massaeli H, Xu J, Jia Z, Wigle JT, Mesaeli N, et al. Extracellular $\mathrm{K}^{+}$concentration controls cell surface density of $I_{\mathrm{Kr}}$ in rabbit hearts and of the HERG channel in human cell lines. $J$ Clin Invest 2009; 119: 2745-2757.

21. Wu X, Zhang J, Liu T, Yan M, Liu H, Xie H, et al. Uric acid crystal could inhibit Numb-induced URAT1 lysosome degradation in uric acid nephropathy. $J$ Physiol Biochem 2015; 71: 217-226.

22. Anzai N, Miyazaki H, Noshiro R, Khamdang S, Chairoungdua A, Shin HJ, et al. The multivalent PDZ domain-containing protein PDZK1 regulates transport activity of renal urate-anion exchanger URAT1 via its C terminus. J Biol Chem 2004; 279: 45942-45950.

23. Kimura T, Takahashi M, Yan K, Sakurai H. Expression of SLC2A9 isoforms in the kidney and their localization in polarized epithelial cells. PLoS One 2014; 9: e84996.

24. Staub O, Gautschi I, Ishikawa T, Breitschopf K, Ciechanover A, Schild L, et al. Regulation of stability and function of the epithelial $\mathrm{Na}^{+}$channel $(\mathrm{ENaC})$ by ubiquitination. EMBO J 1997; 16: 6325-6336.

25. Kato M, Ogura K, Miake J, Sasaki N, Taniguchi S, Igawa O, et al. Evidence for proteasomal degradation of Kv1.5 channel protein. Biochem Biophys Res Commun 2005; 337: 343-348.

26. Ward CL, Omura S, Kopito RR. Degradation of CFTR by ubiquitin-proteasome pathway. Cell 1995; 83: 121-127.

27. Gong Q, Keeney DR, Molinari M, Zhou Z. Degradation of trafficking defective LQT2 mutant channels by the ubiquitin proteasome pathway. J Biol Chem 2005; 13: 19419-19425.

28. Knochel JP, Dotin LN, Hamburger RJ. Heat stress, exercise, and muscle injury: Effects on urate metabolism and renal function.
Ann Int Med 1974; 81: 321-328.

29. Roncal-Jimenez CA, Sato Y, Milagres T, Andres Hernando A, García G, Bjornstad P, et al. Experimental heat stress nephropathy and liver injury are improved by allopurinol. Am J Physiol Renal Physiol 2018; 315: F726-F733.

30. Kang DH, Park SK, Lee IK, Johnson RJ. Uric acid-induced C-reactive protein expression: Implication on cell proliferation and nitric oxide production of human vascular cells. $\mathrm{J} \mathrm{Am} \mathrm{Soc}$ Nephrol 2005; 16: 3553-3562.

31. Maharani N, Ting YK, Cheng J, Hasegawa A, Kurata Y, Li P, et al. Molecular mechanisms underlying urate-induced enhancement of Kv1.5 channel expression in HL-1 atrial myocytes. Circ J 2015; 79: 2659-2668

32. Chong KW, Chen MJ, Koay ES, Wong BS, Lee AY, Russo-Marie $\mathrm{F}$, et al. Annexin A3 is associated with cell death in lactacystinmediated neuronal injury. Neurosci Lett 2010; 485: 129-133.

33. Suh J, Lee YA, Gwag BJ. Induction and attenuation of neuronal apoptosis by proteasome inhibitors in murine cortical cell cultures. J Neurochem 2005; 95: 684-694.

34. Sun F, Kanthasamy A, Song C, Yang Y, Anantharam V, Kanthasamy AG. Proteasome inhibitor-induced apoptosis is mediated by positive feedback amplification of $\mathrm{PKC} \delta$ proteolytic activation and mitochondrial translocation. J Cell Mol Med 2008; 12: 2467-2481.

\section{Supplementary Files}

Please find supplementary file(s);

http://dx.doi.org/10.1253/circrep.CR-20-0016 